\title{
Autoavaliação das escolas: o caso do grupo disciplinar de Biologia/Geologia
}

\author{
Maria João de Carvalho ${ }^{a}$ \\ Helena Correia ${ }^{b}$
}

\section{Resumo}

A investigação de que se dá conta neste artigo teve como objetivo conhecer o modo de concretização do processo de autoavaliação e o seu impacto ao nível da prestação do serviço educativo, concretamente no concernente às práticas docentes do grupo disciplinar de Biologia/Geologia. Sustentado por uma opção que recaiu sobre uma escola pública secundária, do norte do país, este estudo de caso, enquanto estratégia metodológica, subordinada ao paradigma interpretativo, teve como instrumentos de recolha de dados a observação participante, a entrevista semiestruturada e a análise documental. A análise de dados seguiu a metodologia de análise de conteúdo por se afigurar a mais adequada face à natureza qualitativa dos dados obtidos. Da investigação realizada foi possível concluir que, apesar da preocupação com a qualidade e a melhoria do serviço educativo prestado, as ações desenvolvidas surgem, predominantemente, como resposta às pressões da Avaliação Externa de Escolas.

Palavras-chave: Autoavaliação. Avaliação externa de escolas. Planos de melhoria. Prestação de serviço educativo.

\section{Introdução}

A avaliação das escolas públicas decorre das mudanças, no mundo global, ao nível das esferas política, económica e social, sobretudo a partir da década de 70 do século XX, conduzindo a uma configuração geopolítica determinada por fatores como a globalização e a reestruturação do estado.

\footnotetext{
a Universidade de Trás-os-Montes e Alto Douro. Trás-os-Montes, Portugal.

b Universidade de Trás-os-Montes e Alto Douro. Trás-os-Montes, Portugal. 
A crise do capitalismo conferiu à educação um papel central, devido à importância que esta tem no desenvolvimento da economia. Neste contexto, a globalização hegemónica neoliberal despoletou mudanças nos sistemas políticos, ao nível da educação, definindo orientações que são assumidas pelos países que fazem parte de organizações como a Organização para a Cooperação e Desenvolvimento Económico, da Organização das Nações Unidas para a Educação, a Ciência e a Cultura e da União Europeia. A esfera educacional é, assim, submetida a intensas pressões supranacionais e transnacionais, no sentido de colocar a educação ao serviço da economia defendendo, para tal, um serviço educativo de qualidade.

É neste quadro que a avaliação das escolas, e a autoavaliação em particular, é apresentada, com o objetivo de contribuir para o aperfeiçoamento ou melhoria educacional. E, assim, sendo, nenhuma avaliação deverá ser de natureza punitiva, pois, no horizonte, deve estar sempre presente a melhoria das práticas e dos sujeitos (SANTIAGO; SANTOS; MELO, 2017). Em Portugal, com a Lei de Bases do Sistema Educativo, Lei no 46/1986, de 14 de outubro de 1986 (PORTUGAL, 1986), a avaliação passa a ser uma imposição legal, com vista a garantir a qualidade de ensino. Todavia, a avaliação do ensino não superior concretizou-se, apenas, com a publicação da Lei $n^{0}$ 31/2002, de 20 de dezembro (PORTUGAL, 2002), na sequência de um processo político de atribuição de autonomia às escolas, responsabilizando cada instituição para a melhoria do seu desempenho, assim como, para promoção do sucesso escolar. O normativo preconiza a avaliação institucional sob a forma de avaliação externa e de autoavaliação (art. $5^{\circ}$ ) sendo, esta última, de caráter obrigatório e a desenvolver-se em permanência (art. $6^{\circ}$ ).

\section{Autoavaliação versus avaliação externa}

Da análise dos programas dos Governos Constitucionais, desde 1985, a avaliação, a qualidade da educação e do sistema educativo, surgem como preocupações e desiderato, com vista à "melhoria da produtividade da economia e da sociedade" (PORTUGAL, 1999-2002 p. 21) pelo que para atingir este objetivo promovem uma cultura de avaliação conjugando as modalidades de avaliação interna com dispositivos de avaliação externa. Com as suas políticas visam "enraizar em todas as dimensões do sistema de educação e formação a cultura e a prática da avaliação e da prestação de contas" (PORTUGAL, 2005-2009, p. 43).

A autoavaliação das escolas emerge, pois, nas políticas educativas no quadro de novos referenciais e de novos instrumentos de governança, associada a conceitos como eficácia, eficiência e qualidade, oriundos do campo económico, mesmo que se silencie que esta última 
pode servir não só no sentido de diminuir mas, também, de aumentar as desigualdades sociais, uma vez que este conceito vem sendo vinculado a uma lógica de mercado que limita a qualidade a um problema de custos e eficiência [...] fazendo-nos concluir que uma educação de qualidade nem sempre se apresenta como um direito de todos, mas como um privilégio daqueles que se mostram mais capazes (CARVALHO, 2009, p. 144).

A letra e o espírito da Lei $n^{\circ}$ 31/2002 supõem a necessária relação que se deve estabelecer entre avaliação externa e autoavaliação, o que suporta a afirmação de Azevedo de que é "no diálogo entre perspectivas internas e externas que as instituições se desenvolvem e melhoram" (2005, p. 7). Nessa linha, a forma mais eficaz de fazer avaliação institucional está na relação sinérgica entre autoavaliação e a avaliação externa, entendida esta última como suporte e interpelação à autoavaliação.

A autoavaliação e avaliação externa devem ser complementares, muito embora possamos reconhecer que prosseguem finalidades distintas (DIAS, 2013). A primeira centra-se na identificação, pelos próprios atores educativos, dos efeitos da sua ação, não dispensando, por isso, a inquirição dos seus porquês (CARVALHO; FOLGADO, 2017), enquanto a segunda destina-se à prestação de contas, tanto à tutela como ao público em geral, e pode mesmo converter-se em "instrumento de auditoria" (LIMA, 2015, p. 1.343). Com efeito, a autoavaliação pode servir de ponto de partida para a avaliação externa, e esta pode favorecer a melhoria da qualidade da autoavaliação pelos efeitos da aprendizagem que produz, nomeadamente, ao nível da construção de indicadores e de instrumentos de recolha de informação. Somos de opinião de que o nível de desenvolvimento da autoavaliação determina os contornos da avaliação externa, ou seja, um processo de autoavaliação sustentado, regular e consequente retirará protagonismo à avaliação externa (DIAS, 2013). Por seu turno, também a avaliação externa pode ser um importante contributo, um elemento estratégico para as escolas implementarem os seus processos de autoavaliação, pois constitui-se, enquanto oportunidade para a escola, se (re)conhecer, se autoquestionar e refletir; fornece indicadores úteis para a construção ou aperfeiçoamento de planos de melhoria e de desenvolvimento; pode contribuir para a tomada de consciência da necessidade de autoavaliação (FIALHO, 2009).

Do trabalho de investigação desenvolvido por Silvestre, Fialho e Cid (2014) foi possível verificar que as reações negativas que surgiram em algumas escolas ${ }^{1}$, aquando da receção dos relatórios da Avaliação Externa, converteram-se, a médio e longo prazo, num efeito positivo pelo impacto provocado na melhoria

Estudo levado a cabo em 10 unidades orgânicas do Alentejo, Portugal. 
da organização. Daqui foi possível concluir que a Avaliação Externa pode estimular e induzir à melhoria, o que implicitamente acaba por confirmar que aquela promove o desenvolvimento de práticas de autoavaliação (FIALHO et al., 2010), considerações que vão na linha de Santiago (2011), e mesmo de Pacheco (2010), quando reconhecem que o impacto da Avaliação Externa nas escolas tem sido, essencialmente, interno, levando a que sejam feitas correções de situações detetadas e classificadas de problemáticas.

\section{As práticas de autoavaliação}

As preocupações com a autoavaliação parecem oscilar entre a conformidade burocrática formal, por parte de uns, enquanto outros, mais coerentes com a conceção de escola como comunidade educativa, orientam a avaliação para a promoção de um projeto crítico e democratizante (SÁ, 2008), como o atesta a investigação comparativa entre Portugal e Brasil levada a cabo por Mendes et al. (2015).

Neste âmbito, não deixa de ser pertinente o questionamento sobre os motivos pelos quais se realiza a autoavaliação e se produz o relatório, o que não excluirá a possibilidade de o processo e o relatório poderem decorrer de uma imposição legal da avaliação de escolas, cumprindo-se, assim, mais uma etapa burocrática e pouco consequente.

$\mathrm{Na}$ tentativa de implementar processos de autoavaliação, as escolas deparam-se com muitos problemas práticos, que geram dúvidas, inseguranças, o que contribui para um certo clima de tensão (FIALHO, 2009). Deste modo, antes de iniciar um processo de autoavaliação é tão fundamental questionar o porquê e o para quê de avaliar a escola, para quem se avalia, o que se avalia, quando e como se avalia e quem deve estar implicado neste processo (SÁ, 2008; FIALHO, 2009).

Não obstante o enquadramento jurídico, as escolas manifestam dificuldades em desenvolver, coerente e sistematicamente, processos de recolha, análise e interpretação de informação pertinente da realidade escolar, com vista a debelar fragilidades, corrigir erros, mudar trajetórias, isto é, caminhar no sentido da mudança e da melhoria da qualidade do serviço prestado (ROCHA, 2013). Daí que pareça fazer sentido considerarmos como relevante o papel desempenhado pelo órgão de gestão em informar e mobilizar toda a comunidade educativa.

É determinante informar sobre as finalidades do processo, o modo de implementação e os efeitos esperados, para evitar, ou mesmo, combater reações de rejeição e conseguir a confiança, a implicação e o comprometimento de todos, pois a "melhoria da qualidade educativa é uma construção coletiva" (DIAS 
SOBRINHO, 2014, p. 722), sendo que a autoavaliação é um processo "colegial, participativo e construtivo" assente numa "lógica de auscultação, envolvimento e responsabilidade" (AZEVEDO, 2005, p.76).

A autoavaliação numa escola pode-se constituir como meio que permite orientar a mudança, concebendo e desenvolvendo planos de ação adequados à realidade de cada escola (QUINTAS; VITORINO, 2013). Se a autoavaliação for meramente decorrente de exigências legais e não corresponder a uma prática consistente, crítica, consolidada e autónoma de cada escola ou agrupamento, os atores educativos, com o passar do tempo, tenderão a naturalizar e ritualizar (ou mesmo a subverter) os procedimentos daí decorrente e, assim, corre o risco de se transformar num processo estéril, incapaz de produzir mudanças na escola (AFONSO, 2010a, 2010b).

Quando as escolas não interpretam o sentido e a função da sua autoavaliação, embora se sintam forçadas a apresentar um relatório, verificam-se que só apostam na forma e não no processo, não resultando daí nenhuma utilidade na promoção da qualidade da organização escolar (QUINTAS; VITORINO, 2013).

Sá (2008) considera que a autoavaliação, além de virtudes, possui o que designa de efeitos colaterais, pelo facto de estar ao serviço de diferentes sujeitos e agendas com distintas racionalidades. Nesta lógica, Costa e Ventura (2005) defendem que os processos de avaliação institucional podem estar a serviço do mercado, do relatório e da melhoria. Quando se olha a escola como uma empresa e cujo objetivo é captar "clientes", então, serve-se do mercado. A avaliação a serviço da produção do relatório é resultado de uma escola que avalia de forma a cumprir com a conformidade legal subjacente a uma burocracia ritualizada, no sentido de verificar tal conformidade, cumprindo um ritual de fachada. Por outro lado, se os destinatários forem a comunidade de aprendizagem, num processo de construção coletiva, desenvolvendo as capacidades profissionais dos seus membros, a avaliação orienta-se para a melhoria. Estes são alguns dos motivos pelos quais é relevante o questionamento relativo aos valores que a incorporam e aos seus beneficiários (GUERRA, 2003).

\section{Desenho metodológico}

A autoavaliação nas escolas públicas está, em Portugal, consagrada como uma obrigatoriedade, segundo a Lei $\mathrm{n}^{\circ} 31 / 2002$ (PORTUGAL, 2002). Contudo, a alteração das práticas letivas, como consequência dessa autoavaliação, não está regulamentada, pelo que consideramos pertinente perceber qual impacto do trabalho produzido pela equipa de autoavaliação na prestação do serviço educativo, no caso concreto, dos professores de Biologia/Geologia. Neste âmbito elaboramos a seguinte pergunta de partida: 
Como se processa a autoavaliação e como o grupo de Biologia/Geologia a incorpora nas suas práticas docentes?

As subquestões elaboradas pretendem direcionar a investigação sendo que, numa primeira fase se reserva ao aprofundar do conhecimento sobre a autoavaliação nas escolas e, numa segunda fase à auscultação acerca das alterações pedagógicas, num grupo disciplinar, após um período de avaliação institucional. Tendo em conta os objetivos do estudo, delineámos as seguintes subquestões:

i. Como se concretiza a autoavaliação?

ii. Qual o contributo do grupo de Biologia/Geologia para a formulação do plano de melhoria?

iii. De que forma o grupo de Biologia/Geologia promove a consecução do plano de melhoria?

iv. Em que medida a autoavaliação se refletiu na prestação de serviço educativo do grupo de Biologia/Geologia?

v. Que alterações se verificaram ao nível das práticas pedagógicas do grupo de Biologia/Geologia, conducentes à melhoria dos resultados escolares?

Definida a problemática, questão e subquestões, o passo seguinte é a delimitação da investigação, através da definição de objetivos, gerais e específicos, do trabalho a desenvolver.

Desta forma, o objetivo geral desta investigação consiste em:

Conhecer o modo como se concretiza a autoavaliação, bem como a incorporação do trabalho que aí se produz nas práticas dos docentes do grupo disciplinar de Biologia/Geologia.

Os objetivos específicos depreendem-se do geral e devem ser formulados de modo a que estes sejam orientados de acordo com o objetivo geral, isto é, "cada objetivo específico deverá estar desenhado para dar resposta a um aspeto que no seu conjunto vá de encontro ao objetivo geral" (PACHECO, 2010, p. 77). A este propósito apresentam-se os seguintes objetivos específicos: 
- Analisar o processo de autoavaliação numa escola, em especial a participação do grupo de Biologia/Geologia;

- averiguar a contribuição do grupo disciplinar de Biologia/Geologia na elaboração/consecução do plano de melhoria;

- compreender as consequências ao nível da prestação de serviço educativo no grupo de Biologia/Geologia, após um processo de autoavaliação; e

- inferir da melhoria da qualidade pedagógica no grupo disciplinar de Biologia/ Geologia após um processo de autoavaliação.

Abraçamos, assim, o paradigma interpretativo para compreender o fenómeno a partir dos dados fornecidos pelo objeto de estudo. Para o efeito, consideramos o estudo de caso, uma escola do norte de Portugal, pública, que passaremos a designar de Escola Ómega.

A escolha dos interlocutores privilegiados foi intencional e recaiu sobre os atores educativos que tiveram ou têm experiência no fenómeno. Assim, colaboraram na entrevista o diretor, dada a pertinência como timoneiro do processo de autoavaliação e da formulação e consecução do plano de melhoria e, sete elementos do grupo de Biologia/Geologia, entre os quais o coordenador e um elemento pertencente à equipa de autoavaliação. Assim, a unidade de contexto é um suporte importante da validade e fidelidade do trabalho do analista (VALA, 1999). Como elementos representantes destas unidades são os textos provenientes das oito entrevistas efetuadas. A cada uma foi atribuída um código, sendo ED a designação para a entrevista realizada ao diretor e, aos docentes do grupo de Biologia/Geologia atribuímos o código EBG (1 a 7), sendo EBG1 o coordenador de grupo, e EBG2, elemento da equipa de autoavaliação.

\subsection{Recolha de dados}

O recurso a várias fontes de evidência é um ponto forte nos estudos de caso, de forma a obter informação suficiente e pertinente (MEIRINHOS; OSÓRIO, 2010).

No nosso caso, a opção recaiu sobre a entrevista semiestruturada, a análise documental e a observação não estruturada participante.

A realização de entrevistas semiestruturadas, gravadas em suporte analógico, com permissão do entrevistado, utilizando um guião com questões previamente 
elaboradas, atendendo aos objetivos e subquestões formuladas, permitiram um grau de abertura e flexibilidade suficiente, potenciadoras da espontaneidade do pensamento dos inquiridos e favorecer a livre expressão.

Realizámos observação não estruturada, uma vez que o investigador integra a organização escolar e o grupo alvo de estudo, através de uma participação direta e pessoal. A observação é participada, pois, pela razão acima mencionada, o investigador integra-se no grupo em estudo, desempenhando as suas funções, ao mesmo tempo que vai recolhendo os dados de que necessita para a investigação (MEIRINHOS; OSÓRIO, 2010).

O recurso a fontes documentais relacionadas com a temática é uma estratégia básica num estudo de caso. A informação recolhida pode servir para contextualizar o caso, acrescentar informação ou para validar evidências de outras fontes.

No âmbito desta investigação recorremos à análise dos normativos legais associados à avaliação institucional (Lei $n^{\circ}$ 31/2002 [PORTUGAL, 2002], Decreto-Lei $n^{0}$ 75/2008 [PORTUGAL, 2008] e Decreto-Lei no 137/2012 [PORTUGAL, 2012], entre outros), ao relatório de Avaliação Externa da Escola Ómega e aos documentos estruturantes da mesma, a saber, Projeto Educativo, Regulamento Interno, Plano de Estudos e Desenvolvimento Curricular, Plano de Melhoria, Relatórios de Autoavaliação, atas de Conselho Pedagógico, da Equipa de Avaliação Interna, do Departamento a que pertence o grupo disciplinar e atas de grupo disciplinar.

\subsection{Análise de dados}

Sendo este estudo de natureza interpretativa, segue um procedimento de análise qualitativa do conteúdo dos documentos internos da escola e dos discursos expressos nas entrevistas, realizada através da análise de conteúdo.

A análise de conteúdo é um método de tratamento de dados muito utilizada na interpretação dos dados de ciências humanas e sociais, abrange iniciativas de explicitação, sistematização e expressão do conteúdo das mensagens, com a finalidade de se efetuarem deduções lógicas e justificadas a respeito dessas mensagens. Possui duas funções, a heurística, que visa a enriquecer a pesquisa exploratória, aumentando a propensão para a descoberta e proporcionando o surgimento de hipóteses quando se examinam as mensagens pouco exploradas anteriormente e, a uma função de administração da prova, ou seja, servir de prova para a verificação apresentadas anteriormente (BARDIN, 1979). 
O nosso corpus da análise é constituído pelos documentos recolhidos, a priori, e organizados por tipologia, sendo sujeitos a uma seleção em função da pertinência entre o tipo de informações contidas nos documentos e o objeto da análise (VALA, 1999). A estes dados juntar-se-ão as informações recolhidas pelas entrevistas e pela observação participada.

Foram criadas duas dimensões gerais para a análise do conteúdo, sem que tenhamos recorrido a qualquer software: (1) Autoavaliação e (2) Plano de melhoria (Quadro).

Partiremos da análise do processo de autoavaliação, uma vez que nos dá uma perspetiva holística de um procedimento que culmina com a elaboração do plano de melhoria fazendo, posteriormente, o enfoque ao nível da sua consecução com vista à melhoria da qualidade da prestação de serviço educativo.

Quadro. Dimensões, categorias e subcategorias de análise.

\begin{tabular}{|c|c|c|}
\hline Dimensões & Categorias & Subcategorias \\
\hline \multirow{5}{*}{ 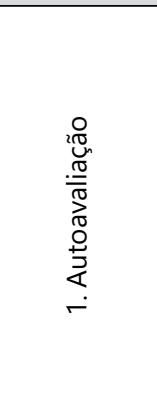 } & $\begin{array}{l}\text { 1.1 Paradigma } \\
\text { subjacente }\end{array}$ & Legislação \\
\hline & \multirow{4}{*}{$\begin{array}{l}1.2 \\
\text { Processo de } \\
\text { Autoavaliação }\end{array}$} & Concretização do processo de Autoavaliação \\
\hline & & $\begin{array}{l}\text { Informação, à comunidade educativa, sobre o processo de } \\
\text { Autoavaliação }\end{array}$ \\
\hline & & Consolidação da autoavaliação na escola \\
\hline & & $\begin{array}{l}\text { Participação dos atores educativos (grupo Biologia/ } \\
\text { Geologia) no processo de Autoavaliação }\end{array}$ \\
\hline \multirow{7}{*}{ 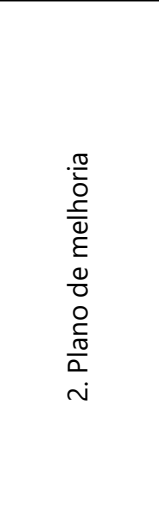 } & \multirow{3}{*}{$\begin{array}{l}\text { 2.1 Elaboração } \\
\text { do plano de } \\
\text { melhoria }\end{array}$} & $\begin{array}{l}\text { Documentos considerados na sua elaboração (relatório de } \\
\text { Avaliação Externa de Escolas e de Autovaliação) }\end{array}$ \\
\hline & & Comunicação da informação \\
\hline & & $\begin{array}{l}\text { Contributos dos docentes de Biologia/Geologia na } \\
\text { elaboração do plano de melhoria }\end{array}$ \\
\hline & \multirow{4}{*}{$\begin{array}{l}2.2 \\
\text { Consecução } \\
\text { do plano de } \\
\text { melhoria pelos } \\
\text { docentes } \\
\text { de Biologia/ } \\
\text { Geologia }\end{array}$} & Contributo dos docentes na consecução do plano \\
\hline & & Participação e empenho na implementação das ações \\
\hline & & Alteração das práticas pedagógicas \\
\hline & & Reflexo na prestação de serviço educativo \\
\hline
\end{tabular}

Fonte: Elaborado pelos autores a partir da investigação (2017). 


\section{Apresentação e análise dos resultados}

\subsection{Processo de Autoavaliação}

A obrigatoriedade da autoavaliação é evidente na Escola Ómega, estando plasmada no art. $64^{\circ}$ do seu Regulamento Interno onde se lê "A autoavaliação tem caráter obrigatório, conta com o apoio de todos os serviços de administração educativa" sendo, também, mencionado no art. $3^{\circ}$ do Regimento da Equipa de Autoavaliação, acrescentando que o processo se desenvolve "em permanência" de acordo com a Lei $n^{\circ}$ 31/2002 (PORTUGAL, 2002). O aspeto impositivo é, mais uma vez, vincado no Relatório de Autoavaliação, onde refere que a "obrigatoriedade da implementação de processos de autoavaliação dos estabelecimentos de ensino não superior foi estabelecida pela Lei n $n^{0} 31 / 2002$ " (Relatório de Autoavaliação, 2009 , p. 4), fazendo referência aos art. $5^{\circ}$ e $6^{\circ}$. As palavras proferidas pelo diretor são mais um exemplo disso, de acordo com a seguinte unidade de registo "existe a obrigatoriedade da implementação de processos de autoavaliação, de acordo com a Lei no 31/2002".

A escola organizou-se, estrutural e funcionalmente, através da criação de uma equipa, cujo papel, em traços gerais, é a concretização da autoavaliação. Cumpridas todas as formalidades legais e regulamentares, bem como o caráter formal das comunicações, coube à referida equipa dinamizar todo o processo. De referir que o discurso proferido pelo diretor, em entrevista, sobre a concretização do processo de autoavaliação é muito articulado, com um elevado grau de semelhança e uma verbalização muito próxima da apresentação textual veiculada nos relatórios de autoavaliação, no parâmetro "metodologia", tal como se pode ler no seguinte excerto:

Para a elaboração do relatório de AA 2014, tiveram-se em conta: atas (conselhos de turma, conselhos de diretores de turma, departamentos, áreas disciplinares, reuniões com encarregados de educação); questionários respondidos pelos professores, assistentes, alunos utilizando a plataforma moodle, e aos pais e Encarregados de educação distribuídos em suporte de papel (correspondendo a uma amostra dos alunos matriculados, de diferentes anos e níveis de ensino) dados relativos a processos disciplinares, em função dos relatórios entregues pela Direção ao Conselho Geral; pautas de avaliação de frequência e exames nacionais (relatórios periódicos da equipa de autoavaliação); relatórios de diferentes estruturas da escola, através do relatório final do plano anual de atividades. Posteriormente, foi feito o tratamento dos dados e elaborado o relatório, que sofreu várias reformulações, aprovados pelo conselho pedagógico e submetidos à apreciação 
do Conselho Geral. Posteriormente, foram divulgados à comunidade educativa, via departamentos, e colocado na página da escola (ED).

De acordo com as informações obtidas através de EBG2 foi possível constatar que recaiu sobre a equipa a maior responsabilização no desenrolar do processo avaliativo, cingindo-se a contribuição da comunidade educativa ao preenchimento dos inquéritos, pois

Para dar andamento ao processo de autoavaliação fomos ler livros e pesquisar como é que funciona noutras escolas. Nós não inventámos a roda. Com base nisso elaborámos inquéritos de auscultação à comunidade educativa (alunos, pais/encarregados de educação, docentes e não docentes), preenchidos na plataforma moodle. Depois de reunir os dados e da análise de outros documentos (relatórios, atas), fizemos o seu tratamento e a sua análise, do qual resultou um relatório [...], que foi tratado e filtrado várias vezes até se obter o relatório final, capaz de ser lido por qualquer pessoa.

A escola foi informada sobre o decorrer do processo de autoavaliação bem como do plano de ação da equipa para o dinamizar. No caso do grupo de Biologia/Geologia tal decorreu, formalmente, em reunião de departamento, onde foi informado que a equipa de Autoavaliação solicitou "a colaboração de todos, nomeadamente nas respostas aos inquéritos que iriam ser aplicados", em conformidade com a ata de 22 de outubro de 2013. Atentando ao solicitado pelo coordenador da equipa, em conselho pedagógico e ao informado em reunião de departamento, verifica-se uma desconexão, que é reiterada pelo teor da ata de conselho pedagógico de 11 de dezembro de 2013, quando o referido coordenador "solicita que os professores preencham o inquérito".

Por observação participante foi possível constatar que a colaboração se limitou ao preenchimento dos questionários e à produção dos relatórios das atividades desenvolvidas, o que converge com as informações obtidas nas entrevistas, como é possível ler nos seguintes exemplos de testemunho: "grupo de Biologia/Geologia, em particular, preencheu os questionários, e elaborou os relatórios de reflexão sobre as atividades. Não mais do que isso" (EBG7); "o grupo não ajudou na elaboração dos instrumentos usados no processo de Autoavaliação, apenas contribuiu preenchendo os questionários e produzindo relatórios de reflexão sobre as atividades realizadas, sobre o trabalho setorial, de grupo, de direção de turma (quem as tem) e sobre análise dos resultados por período" (EBG6); "houve contributo no sentido em que responderam aos inquéritos, mas, de resto, não houve. As pessoas receberam 
os inquéritos prontos a preencher, e fizeram-no, provavelmente, porque era obrigatório" (EGB2). Os restantes entrevistados forneceram informações similares. A explicação para essa intervenção assimétrica é avançada pelo diretor quando refere que

Obviamente que os atores educativos terão um contributo mais ou menos significativo, dependendo, também, da própria vontade em envolver-se no processo. Há pessoas que se predispõem mais para se envolverem, pois, trata-se de uma área com que nem todos se identificam. Logicamente que, assim sendo, a equipa de autoavaliação tem de ser muito mais interventiva e, tentar ter uma atitude de dinâmica completamente diferente do que algumas equipas, constituídas naturalmente, no interior da escola. De qualquer forma, todos os atores educativos são envolvidos, quando mais não seja, no preenchimento dos inquéritos (ED).

Durante as entrevistas foi possível constar que a comunidade foi informada sobre o decorrer da autoavaliação, como refere a unidade de contexto supramencionada do entrevistado EBG3, corroborada pelo diretor, quando diz que "O projeto de autoavaliação, [...], foi divulgado à escola através do conselho pedagógico, tendo sido solicitado a todos a disponibilidade para colaborar com a equipa" (ED); assim como pelo docente EBG7 "sabia-se, na escola, que estava a decorrer um processo de autoavaliação". Em conformidade o EGB6 declara que

A comunidade é informada que o processo de autoavaliação está a ser realizado, até porque se preenchem os questionários. No final, o relatório vai ao conselho pedagógico e, depois, baixa aos departamentos, via coordenador de departamento (por email institucional), para ser lido pelos docentes e, posteriormente, analisado em reunião de departamento.

É indubitável a comunicação formal da ocorrência de um procedimento da escola, embora por imposição legal, sendo clara a existência de uma hierarquia da autoridade, pois são produzidos documentos e tomadas as decisões em estruturas hierarquicamente superiores (o conselho pedagógico) e, posteriormente, comunicadas aos atores educativos, seguindo estruturas intermédias, o coordenador de departamento. Todavia, alguns elementos do grupo disciplinar não conhecem com clareza todas as etapas do processo de autoavaliação: "Não sei precisar muito bem, duas, três?" (EBG6) 
Sendo a autoavaliação um procedimento imposto, importa saber se se trata de um acontecimento pontual ou se há uma prática de autoavaliação consolidada. Para dar resposta a esta questão, começámos por verificar o que era feito na Escola Ómega, com base no teor das atas de conselho pedagógico e de departamento e na observação participante. Constatámos que, desde que se iniciou o primeiro processo de autoavaliação, em 2008/2009, esta organização escolar tem levado a cabo a elaboração de relatórios periódicos de análise dos resultados dos alunos, com base nas pautas de avaliação de final de período. No início de cada ano letivo são apresentados relatórios referentes à análise dos resultados obtidos em exame, no ano letivo anterior, e cruzados dados com os da avaliação interna. Tal é explanado em ata de conselho pedagógico, de 16 de outubro de 2013, designadamente quando se lê que "será elaborado um relatório relativo aos resultados de avaliação externa da escola (exames nacionais), será feito um estudo acerca da concretização do plano de melhoria e elaborado o respetivo relatório, que sirva de apoio ao processo de atualização do projeto educativo, e serão feitos relatórios trimestrais dos resultados escolares".

Os relatórios são analisados em reunião de conselho pedagógico, como pode ler-se no seguinte fragmento, extraído da ata de 29 de outubro de 2013, "Dando cumprimento ao ponto dois da ordem de trabalhos - Análise dos resultados escolares relativos ao $1^{\circ}$ Período - cada coordenador fez uma análise relativa aos resultados das disciplinas do seu departamento". Esses relatórios são aprovados em conselho pedagógico e enviados para serem alvo de análise nos departamentos.

A produção de relatórios de avaliação de resultados confunde-se com uma prática de avaliação consolidada, tal como espelha o seguinte extrato:

Neste momento, são feitas, todos os períodos, a recolha e análise da avaliação dos alunos, no que respeita aos seus resultados, sendo feito um relatório que, mais uma vez, é disponibilizado a todos via coordenador de departamento e analisado por quem estiver interessado (EBG1).

Opinião partilhada pelos entrevistados EBG3 e EBG5 ao mencionarem que

Nos últimos anos têm sido feitos, com regularidade, relatórios de Autoavaliação, dos resultados escolares de uma forma mais frequente e, menos, das diferentes estruturas da escola (EBG3). 
Existem vários instrumentos que têm sido postos em prática, no sentido de fazer uma Autoavaliação consistente, ao longo dos anos. Reflexão ao nível de departamento e de grupo sobre os relatórios trimestrais (dos resultados escolares) (EBG5).

Foi possível verificar a manifestação de algumas reticências quanto aos efeitos da mesma quando declaram que

A escola como um todo tem uma avaliação consolidada no sentido em que, em termos de AA faz o que é obrigada a fazer por lei. $\mathrm{O}$ relatório de AA é o resultado dessa obrigatoriedade. Se essa AA introduz muitas mudanças? Não sei se introduz. Algumas!? (EBG2).

A escola faz AA regularmente. Por isso, conhece quais são os seus aspetos mais positivos e menos positivos. Se essa Autoavaliação tem resultados concretos na melhoria da ação? Aí já tenho algumas dúvidas em responder (EBG6).

A consolidação da autoavaliação é considerada ponto assente por todos os entrevistados, aludindo à produção de relatórios trimestrais de análise estatística dos resultados dos alunos e dos relatórios de autoavaliação das diferentes dimensões da escola, os quais são enviados aos docentes, para análise e reflexão.

Apesar dos procedimentos de autoavaliação existirem e dos relatórios serem previamente enviados aos docentes, é possível, por observação participada, verificar que nem todos os elementos do grupo os leem, efetuando-se o primeiro contacto aquando da análise em grupo disciplinar. Deste modo, não há apropriação dos resultados da Autoavaliação formalizados nos relatórios produzidos. O grau de participação dos diferentes atores é variável, entre o ativo e o reservado, pois.

A verdade é que muitas vezes quase forçamos a leitura destes documentos, em reunião de departamento, ao analisarmos os resultados desses relatórios. Muitas pessoas continuam a ter uma postura muito individual, quando se trata de autoavaliar o processo educativo. Sinto, realmente, que nem toda a gente, apesar do sistema informático via email fazer chegar a todos, com celeridade todos os documentos, nem toda a gente tem empenho em lê-los (EBG1).

Pelo que foi analisado nesta categoria, Processo de avaliação, foi possível analisar o modo como se processa a autoavaliação na escola, e responder, por isso, à pretensão inclusa no primeiro objetivo específico. 


\subsection{Plano de Melhoria}

\subsubsection{O plano de melhoria e a sua prática: os docentes de Biologia/Geologia}

No seu plano de melhoria a Escola Ómega evidencia os vários documentos legais a que estão obrigados para a concretização deste processo, sendo que, de acordo com o expresso na ata de conselho pedagógico de 29 de outubro de 2014, o

coordenador da equipa da avaliação interna, [...] sublinhou que o Plano de Melhoria apresentado é um documento seletivo, sintético e pragmático e que vem dar resposta ao que foi apresentado/ recomendado pela Inspeção Geral de Educação e Ciência no âmbito da sua última avaliação externa na escola.

Na sequência de um pedido de colaboração, promovido superiormente e formalmente comunicado, foram preenchidos os documentos "Cultura de melhoria eficaz da escola" e "Ficha de ação de melhoria", em reunião de departamento, com base na análise dos relatórios de Autoavaliação e da avaliação Externa de Escolas.

Através da observação foi possível constatar o desconhecimento de alguns elementos do grupo em relação aos pontos fracos e recomendações, do relatório de Avaliação Externa de Escolas, verbalizados pela coordenadora, o que revela um certo alheamento.

O trabalho de reflexão e as propostas avançadas basearam-se, essencialmente, nos pontos fracos e recomendações que constavam no relatório de Avaliação Externa de Escola.

Tendo em conta os diversos relatórios e, principalmente, o relatório de Avaliação Externa quanto às áreas onde a Escola deve incidir, prioritariamente, os seus esforços para a melhoria, o grupo disciplinar apresentou ações de melhoria em dois campos de ação prioritária: A identificação dos fatores explicativos do (in)sucesso que permitam a definição de estratégicas sustentadas, visando à melhoria dos resultados; Acompanhamento e supervisão da prática letiva em contexto de sala de aula enquanto forma de melhoria do desenvolvimento profissional. Cruzando as atividades propostas pelo grupo disciplinar de Biologia/Geologia com o plano de melhoria da escola, verificou-se que foram generalizadas a todos os departamentos da escola. Considerações que respondem ao segundo objetivo específico por nós aventado.

O plano de melhoria resulta, pois, da compilação, pela equipa de autoavaliação, das propostas de ação de melhoria, oriundas dos diferentes departamentos 
curriculares, após reflexão suportada nos relatórios de Autoavaliação e de Avaliação Externa de Escolas, situação que pode deixar em aberto a possibilidade de ser uma manta de retalhos.

De acordo com que foi possível observar, e considerando o terceiro objetivo específico, as ações foram implementadas e, aparentemente, bem aceites e concretizadas por todos. Todavia, a partir da observação, constatou-se a ocorrência de alguns reparos feitos pelo coordenador de departamento, no sentido de todos cumprirem com algumas decisões tomadas em grupo, mormente no que respeita à elaboração de matrizes, tipologia e número de questões e critérios de correção dos testes.

No que à sala de aula diz respeito, "a supervisão em sala de aula não foi concretizada", aspeto que foi mencionado por todos os entrevistados do grupo de Biologia/Geologia, sendo que, em conformidade com a ata de departamento de 9 de setembro de 2014, alguns consideram que "o trabalho em equipa setorial é uma forma de supervisão".

As reações, observadas, em relação à operacionalização da ação, por parte de alguns, foram no sentido de sub-repticiamente condicionar a sua execução ao expressar "a sua dificuldade em perceber como se vai efetivar esta supervisão, face ao facto de já termos muitas horas de trabalho na escola ocupadas com outras tarefas", ou concordando com a "dificuldade da operacionalização" apesar de considerarem que a "supervisão poderia ser uma mais-valia para ultrapassar" situações como "adequação dos testes que aplicamos à forma como ensinamos e àquilo que ensinamos", declarações em conformidade com o redigido em ata de departamento de 25 de outubro de 2014. Na mesma reunião, foi referido que "na altura em que se discutiu esta proposta havia alguma pressão de tempo e concordou-se com a proposta do colega X, reforçar o trabalho setorial".

Concluiu-se que a elaboração do plano de melhoria resulta da obrigatoriedade de o fazer, transparecendo a racionalidade instrumental na dinâmica organizacional. No entanto, de acordo com as palavras do coordenador e do observado, a elaboração do plano de melhoria não teve o envolvimento ativo de todos.

Quando questionados sobre se se sentia o impacto do trabalho desenvolvido pela equipa de autoavaliação, ao nível da prestação de serviço educativo, os interlocutores privilegiados reconhecem que "engloba toda a comunidade educativa e, apesar de haver melhorias pontuais num ou noutro grupo, nem todos conseguem levar a bom porto as medidas que são propostas". 
Foi possível observar que os docentes de Biologia/Geologia colocam em prática a maioria das ações do plano, estando em conexão com o mesmo. As reuniões setoriais, o reforço de aprendizagem contemplado no horário do professor, a aplicação de testes uniformizados, a análise dos resultados escolares, entre outros, são tarefas desenvolvidas em função dos objetivos da Escola Ómega. No entanto, no que respeita à ação individual, em ambiente de sala de aula, há indícios de desarticulação, revelando que os objetivos da organização escolar não são partilhados igualmente por todos, resultando na inconsequência das ações institucionais, pelo não cumprimento integral das decisões, pressupostos que nos permitem inferir sobre a melhoria da qualidade pedagógica incorporada no quarto objetivo específico.

\section{Conclusão}

Da investigação realizada foi possível concluir que, apesar da preocupação com a qualidade e melhoria do serviço educativo prestado, o tipo e grau de participação praticada no processo de autoavaliação não é idêntico para todos os atores educativos, e que as ações desenvolvidas surgem, maioritariamente, como resposta às pressões da avaliação externa. Com efeito, o impacto da autoavaliação é sentido ao nível de algumas medidas educativas tomadas, nomeadamente ao nível da promoção do reforço de aprendizagem a disciplinas basilares, aplicação de testes uniformizados, reuniões alargadas de conselho de turma e planeamento comum das atividades a desenvolver numa disciplina/ano, em reuniões setoriais. Contudo, a não operacionalização da supervisão pedagógica, como ação do plano de melhoria, não tornou percetível a ocorrência de mudanças na prestação do serviço educativo em ambiente de sala de aula. Todo o esforço empreendido nos processos de autoavaliação traduz-se no cumprimento de uma imposição político-normativa, bem como num ritual legitimador e de gerenciamento da imagem da escola pública. Não obstante, há o reconhecimento da importância dos resultados da avaliação institucional (interna e externa) na imagem refletida para a sociedade envolvente.

Inerente ao facto de se tratar de um estudo de caso, está a impossibilidade de se generalizarem as nossas conclusões às restantes escolas públicas portuguesas ou a outros grupos disciplinares.

Por isso, em termos futuros, consideramos pertinente o alargamento deste estudo aos restantes grupos disciplinares e estruturas desta, ou outra, organização escolar, bem como a auscultação da perspetiva de outros atores educativos que não os docentes. 


\title{
Self-assessment of schools: the case of the Biology/Geology disciplinary group
}

\begin{abstract}
The research presented here analyzes the self-evaluation process and the impact of the work of self-assessment teams on the provision of educational services, namely on Biology and Geology teaching practices. The study, grounded in an interpretive approach, was developed in a public secondary school in northern Portugal. Data was collected through participant observation, semi-structured interviews and documental analysis, and analyzed through content analysis, which was deemed the most suitable approach to processing the data collected. Results indicate that, despite concerns with quality and improvement of educational services, the measures that have actually been implemented respond mostly to the pressure brought about by the schools' external assessment.
\end{abstract}

Keywords: Self-assessment. Schools' external assessment. School improvement plans. Educational services.

\section{Autoevaluación de las escuelas: el caso del grupo disciplinario de Biología/Geología}

\section{Resumen}

La investigación de que trata este artículo tuvo como objetivo conocer el modo de realización del proceso de autoevaluación y su impacto al nivel de la prestación del servicio educativo, especificamente con respecto a las prácticas docentes en la asignatura de Biología/ Geología. Basado en la elección de una escuela pública del norte del país con enseñanza secundaria y enseñanza básica, este estudio de caso, como estrategia metodológica, subordinada al paradigma interpretativo, tuvo como instrumentos de recolección de datos la observación participativa, la entrevista semiestructurada y el análisis documental. El análisis de datos siguió la metodología de análisis de contenido por parecer ser la más adecuada frente a la naturaleza cualitativa de los datos obtenidos. Con relación a la investigación realizada ha sido posible concluir que, aunque haya preocupación por la calidad y la mejora del servicio educativo ofrecido, las acciones desarrolladas surgen, solamente, como respuesta a las presiones de la Evaluación Externa de las Escuelas.

Palabras clave: Autoevaluación, Evaluación externa de escuelas; ; Planes de mejora; Prestación de servicio educativo. 


\section{Referências}

AFONSO, A. J. Notas sobre auto-avaliação da escola pública como organização educativa complexa. ELO 17 Auto-avaliação das Escolas e Processos de Auto-monitorização, p. 13-21, 2010b. Disponível em: <http:// docplayer.com.br/9790879-Elo-17-auto-avaliacao-das-escolas-e-processos-deauto-monitorizacao.html>. Acesso em: 9 maio 2016.

Políticas educativas e autoavaliação da escola pública portuguesa. Apontamentos de uma experiência. Estudos em Avaliação Educacional, v. 21, n. 46, p. 343-61, 2010a. https://doi.org/10.18222/eae214620102016

AZEVEDO, J. M. Avaliação das escolas: fundamentar modelos e operacionalizar processos. In: PORTUGAL. Ministério da Educação. Conselho Nacional de Educação. Avaliação das escolas: modelos e processos. Lisboa: Conselho Nacional de Educação, 2005.

BARDIN, L. Análise de conteúdo. Lisboa: Edições 70, 1979.

CARVALHO, M. J. No trajecto das racionalidades decisórias da organização escolar. Educação, Sociedade \& Culturas, n. 29, p. 141-55, 2009.

CARVALHO, M. J., FOLGADO, C. Autoavaliação na construção da escola democrática. Revista Lusófona de Educação, v. 35, p.83-98, 2017. https://doi.org/10.24140/issn.1645-7250.rle35.05

COSTA, J.; VENTURA, A. Avaliação e desenvolvimento organizacional. Infância e Educação - Investigação e Práticas, n. 7, p. 148-61, 2005.

DIAS, M. (Coord.) Concepção estratégica das intervenções operacionais no domínio da educação: relatório final. Lisboa: Escola Superior de Educação, 2013. (Estudos Horizonte 2013. Formulação de políticas públicas no horizonte 2013).

DIAS SOBRINHO, J. Avaliação ética e política em função da educação como direito público ou como mercadoria? Educação \& Sociedade, v. 25, n. 88 esp., p. 703-25, out. 2013.

FIALHO, I. A qualidade de ensino e a avaliação das escolas em Portugal: contributos para a sua história recente. Educação. Temas e problemas Avaliação, Qualidade e Formação, v. 7, n. 4, p. 99-116, 2009.

FIALHO, I. et al. Avaliação, escola e excelência. Indícios organizacionais de uma relação íntima. In: CONGRESSO DA AEPEC - Da exclusão à excelência. 
Caminhos Organizacionais para a qualidade da Educação, 11., Évora, Portugal. Comunicação.... Évora: Universidade de Évora, 2010. p. 1-14.

GUERRA, M. Tornar visivel o quotidiano. Porto: Edições ASA, 2003.

LIMA, L. A avaliação institucional como instrumento de racionalização e o retorno à escola como organização formal. Educação e Pesquisa, v. 41, n. spe, p. 1339-52, dez. 2015. https://doi.org/10.1590/S1517-9702201508142521

MEIRINHOS, M.; OSÓRIO, A. O estudo de caso como estratégia de investigação em educação. EDUSER: Revista de Educação, v.2, n. 2, P. 49-65, 2010.

MENDES, G. et al. Autoavaliação como estratégia de resistência à avaliação externa ranqueadora. Educação e Pesquisa, v. 41, n. spe , p.1283-98, 2015. https://doi.org/10.1590/S1517-9702201508144828

PACHECO, J. A. Avaliação externa das escolas: teorias e modelos. In: SEMINÁRIO “AVALIAÇÃO EXTERNA DAS ESCOLAS: TEORIAS, PRÁTICAS E IMPACTO”, 2010, Braga, Portugal. Comunicação... Braga: Universidade do Minho, 2010.

PORTUGAL. Decreto-Lei No 75/2008, de 22 de abril de 2008. Aprova o regime de autonomia, administração e gestão dos estabelecimentos públicos da educação pré-escolar e dos ensinos básico e secundário. Diário da República. 22 abr. 2008.

. Decreto-Lei No 137/2012, de 2 de julho de 2012. Este decreto-lei procede à segunda alteração ao Decreto-Lei n. ${ }^{\circ} 75 / 2008$, de 22 de abril, alterado pelo Decreto-Lei n. ${ }^{\circ} 224 / 2009$, de 11 de setembro, que aprova o regime de autonomia, administração e gestão dos estabelecimentos públicos da educação pré-escolar e dos ensinos básico e secundário. Diário da República. 2 de jul 2012.

. Lei $\mathrm{N}^{\mathrm{o}} 31$, de 20 de dezembro de 2002. Aprova o sistema de educação e do ensino não superior, desenvolvendo o regime previsto na Lei n.o 46/86, de 14 de Outubro (Lei de Bases do Sistema Educativo). Diário da República. 20 dez. 2002.

. Lei ${ }^{\circ}$ 46, de 14 de outubro de 1986. Lei de Bases do Sistema Educativo. Diário da República. out. 1986.

PORTUGAL. Presidência do Conselho de Ministros. Programa do XIV Governo Constitucional. [S. L.], 1999-2002.

. Presidência do Conselho de Ministros. Programa do XVII

Governo Constitucional. [S. L.], 2005-2009. 
QUINTAS, H.; VITORINO, T. Avaliação externa e auto-avaliação das escolas. In: VELOSO, L. (Org.). Escolas e avaliação externa: um enfoque nas estruturas organizacionais. Lisboa: Mundos Sociais, 2013. p. 7-25.

ROCHA, A. A autoavaliação nas escolas portuguesas: diagnóstico com base nos resultados da avaliação externa. Cadernos da Pedagogia. São Carlos, v. 6, n. 12, p. 116-28, jan./jun. 2013.

SÁ, V. A (auto)avaliação das escolas: "Virtudes" e "Efeitos Colaterais". Ensaio: Avaliação das Políticas Públicas em Educação, v. 17, n. 62, p. 87-108, jan./mar. 2008. https://doi.org/10.1590/S0104-40362009000100005

SANTIAGO, M. C.; SANTOS, M. P.; MELO, S. C. Inclusão em educação: processo de avaliação em questão. Ensaio: Avaliação e Políticas Públicas em Educação, v. 25, n. 96, p. 632-51, 2017. https://doi.org/10.1590/s0104-40362017002500652

SANTIAGO, P. Avaliação de escolas: um quadro conceptual e práticas internacionais. In: SEMINÁRIO AVALIAÇÃO DAS ESCOLAS DOS ENSINOS BÁSICO E SECUNDÁRIO: PERSPECTIVAS PARA UM NOVO CICLO AVALIATIVO, 2010, Lisboa, Portugal. Actas... Lisboa: Conselho Nacional de Educação, 2011. p. 27-51.

SILVESTRE, M.; FIALHO, I.; CID, M. Efeitos da avaliação externa das escolas nos resultados escolares e na qualidade do serviço educativo prestado. In: FIALHO, I. et al. Políticas educativas, eficácia e melhoria da escola. Évora: Centro de Investigação em Educação e Psicologia da Universidade de Évora, 2014. p. 103-22.

VALA, J. A análise de conteúdo. In: SILVA, A. S.; PINTO, J. (Orgs.). Metodologia das ciências sociais. 10a ed. Porto: Edições Afrontamento, 1999. p. 101-28.

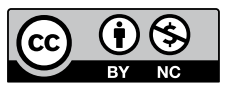

\section{Informações das autoras}

Maria João de Carvalho: Professora Auxiliar da Universidade de Trás-os-Montes e Alto Douro (UTAD). Investigadora do Centro de Investigação e Intervenção Educativas (CIIE) da Universidade do Porto. Diretora do Doutoramento em Ciências da Educação da UTAD. Diretora do Mestrado em Ciências da Educação: área de especialização em Administração Educacional da UTAD. Contato: mjcc@utad.pt

Helena Correia: Mestre em Ciências da Educação, com área de especialização em Administração Educacional, pela Universidade de Trás-os-Montes e Alto (UTAD). Contato: helena.ic.correia@gmail.com 